\title{
Multi-tool formaldehyde measurement in simulated and real atmospheres for indoor air survey and concentration change monitoring
}

\author{
Laura Chiappini - Romain Dagnelie - Maria Sassine • \\ Faustina Fuvel • Sebastien Fable • Thu-Hoa Tran-Thi • \\ Christian George
}

Received: 22 October 2009 /Accepted: 8 October 2010 /Published online: 21 October 2010

(C) The Author(s) 2010. This article is published with open access at Springerlink.com

\begin{abstract}
Formaldehyde is of particular health concern since it is carcinogenic for human and ubiquitous in indoor air where people spend most of their time. Therefore, it is important to have suitable methods and techniques to measure its content in indoor air. In the present work, four different techniques have been tested in the INERIS exposure chamber and in indoor environments in comparison to a standard active method: passive sampling method based on the reaction of 2,4-dinitrophenylhydrazine with formaldehyde, two on-line continuous monitoring systems based on fluorescence and UV measurements and a portable commercialised analyser based on electrochemical titration. Two formaldehyde concentrations, about 10 and $25 \mu \mathrm{g} \mathrm{m}^{-3}$ were generated in an exposure chamber under controlled conditions of temperature, relative humidity, and wind speed to simulate real conditions and assess potential influence on passive sampling and continuous systems response. Influence of sampling periods on passive sampling has also been evaluated. The real atmosphere experiments have been performed in four different indoor
\end{abstract}

L. Chiappini $(\triangle) \cdot$ F. Fuvel $\cdot$ S. Fable

Direction des Risques Chroniques (DRC),

Unité Chimie Métrologie Essais (CIME),

Institut National de l'Environment Industriel et des Risques,

Verneuil-en-Halatte, France

e-mail: laura.chiappini@ineris.fr

R. Dagnelie $\cdot$ T.-H. Tran-Thi

CEA Saclay,

Gif-sur-Yvette, France

M. Sassine $\cdot$ C. George

IRCELYON, Institut de Recherches sur la Catalyse et

l'Environnement de Lyon, UMR5256,

Villeurbanne, France environments: an office, a furniture shop, a shopping mall, and residential dwellings in which several potential formaldehyde sources linked to household activities have been tested. The analytical and sampling problems associated with each measurement method have been identified and discussed. An overall agreement between each technique has been observed and continuous analyzers allowed for formaldehyde concentrations change monitoring and secondary formation of that pollutant observation.

Keywords Formaldehyde - Indoor survey · Passive sampling $\cdot$ Monitoring $\cdot$ Secondary formation

\section{Introduction}

Formaldehyde is one of the major indoor air pollutants due to its human health effects, it has been classified in group 1 (human carcinogen) by the International Agency for Research on Cancer (IARC 2004), and its various emission sources. These sources can be either continuous like resins used for wood manufacture products (Brown 1999; Loh et al. 2006) or intermittent such as cigarette smoke and combustion processes. Formaldehyde can also be formed as a secondary product from volatile organic compounds oxidation such as terpenes (Bonn et al. 2002; Wolkoff et al. 2008) which are widely used in domestic cleaning products and air fresheners (Nazaroff and Weschler 2004). Usually much higher than outdoor concentrations, indoor formaldehyde levels can consequently reach rather high values like $125 \mathrm{\mu g} \mathrm{m}^{-3}$ in residential environments (Zhang et al. 1994) and be of health concern. In French dwellings, average formaldehyde levels vary from 3 to $60 \mathrm{\mu g} \mathrm{m}^{-3}$ (Observatory on Indoor Air Quality (OQAI) 2006). 
Since people spend most of the time in indoor environments, it is essential to be provided with reliable and accurate analytical techniques to assess their exposure to formaldehyde. Therefore many techniques have been developed for formaldehyde measurements and among them indirect methods, based on formaldehyde derivatization, for concentration monitoring and population exposure survey and on-line continuous methods for source emissions and concentration variation monitoring.

As for indirect method, there are two international standards methods for formaldehyde measurement in indoor environments, respectively, for active sampling (ISO 160003:2001, 2001) and passive sampling (ISO 16000-4:2001, 2004). Both are based on the reaction of the carbonyl function with 2.4-dinitrophenylhydrazine (DNPH) to form an UV emitting chromophore, hydrazone. They are widely used for formaldehyde measurement (Andreini et al. 2000; Bates et al. 2000; Gillett et al. 2000; Hanoune et al. 2006; Huynh and Vu-Duc 2002; Marchand et al. 2006). Another standard procedure (Nash 1953), the acetyl acetone method based on the Hantzsch reaction is also widely applied. It has been compared with DNPH active sampling by Salthammer and Mentese 2008 who have shown a good agreement between both techniques for formaldehyde measurement.

Many other derivatisation agents have been tested on other sampling medium such as passive sampling based on CENT (O-(4-cyano-2-ethoxybenzyl) hydroxylamine) (Onishi et al. 2007), Fluoral-P derivatization which is formaldehyde specific and UV detection (Pinheiro et al. 2004), 2.3.4.5.6-PENTAFLUOROBENZYLHYDROXYLAMINE derivatization followed by solid-phase microextraction (Koziel et al. 2001) or thermodesorption and gas chromatography detection (Ho and Yu 2002).

Other issues linked to formaldehyde monitoring are the identification of its sources and the evaluation of its secondary contribution to total indoor air concentration. Continuous on-line measurements appear to be a good way to characterize sources and assess reactive chemistry phenomenon. The in situ spectrometric methods such as Fourier transform infrared spectroscopy (Hak et al. 2005), differential optical absorption spectroscopy Cardenas et al. 2000 or tunable diode laser absorption spectroscopy (Sauer et al. 2001) are very sensitive and specific but expensive and cumbersome and not adapted to indoor measurement. Since few commercialized techniques are available for online formaldehyde measurement (The AEROLASER ${ }^{\circledR}$, Bell et al. 2000; Wisthaler et al. 2008, and the INTERSCAN ${ }^{\circledR}$ ) many techniques are being developed in many research laboratory such as a portable system based on photodetection (Toda et al. 2005) or an analyzer based on fluorometry detection (Eom et al. 2008).

Among all these techniques, the ability of four have been tested in the INERIS exposure chamber and in various indoor environments in comparison with the standard active method sampling on Sep-Pack cartridges: two on-line continuous monitoring systems based on fluorescence (Paolacci et al. 2007) and UV measurements, a portable commercialized analyzer based on electrochemical titration (INTERSCAN ${ }^{\circledR}$ ) and passive sampling methods on Radiello ${ }^{\circledR}$ cartridge based on the reaction of DNPH with formaldehyde. Even if this latest has been widely used (Andreini et al. 2000; Bates et al. 2000; Clarisse et al. 2003) formaldehyde uptake on passive samplers depends on many environmental parameters (temperature, relative humidity, wind speed...), sampling time or formaldehyde concentration which cannot be controlled as well as flow rate for active sampling and whose influence on formaldehyde uptake rate has to be addressed.

Therefore this paper on the one hand points out some parameters which have to be taken into account when measuring formaldehyde in indoor environment with passive samplers and on the other hand emphases the need to be provided with continuous measurement method specially to discriminate formaldehyde primary and secondary emissions, identify sources and consequently better reduce them.

\section{Experimental}

Description of formaldehyde concentration measurement instruments

Table 1 overviews the instruments used for this study and tested in simulated and real atmosphere conditions.

Both off-line methods, active and passive sampling, were based on DNPH reaction, solvent extraction and highperformance liquid chromatography (HPLC)-UV analysis which were carried out using a ternary gradient (acetonitrile/water/THF — water/acetonitrile - acetonitrile) HPLCsystem from Dionex Corporation (Voisins Le Bretonneux, France) equipped with a multiwavelengths UV/VIS detector operating at $365 \mathrm{~nm}$ for formaldehyde detection. The analytical column was an ALTIMA $(\mathrm{C} 18,150 \times 3 \mathrm{~mm}$, $3 \mu \mathrm{m})$ purchased from Altech (Toronto, Ontario) and the separation was carried out with a solvent flow rate of $0.6 \mathrm{ml} \mathrm{min}^{-1}$.

Active sampling tubes were Sep-Pack ${ }^{\circledR}$ cartridge purchased from Waters (Guyancourt France). The air flow through the cartridges was set to $1 \mathrm{~L} \min ^{-1}$, controlled with a flow controller Gillibrator ${ }^{\circledR}$ before and after each sampling. The total sampled volume is also controlled with a gasmeter. A KI ozone filter was used to prevent negative artifacts linked to hydrazone ozonolisis (Bates et al. 2000). Sampling lasted a few hours so that they could cover the whole passive tube exposure time period. 
Table 1 Overview of the instruments and their characteristics deployed for the study

\begin{tabular}{|c|c|c|c|c|}
\hline Method & Naming & Detection principle & Time resolution & Detection limit $\mu \mathrm{g} \mathrm{m}^{-3}$ \\
\hline Active sampling & Sep-Pack ${ }^{\circledR}$ cartridge & DNPH derivatization HPLC analysis & $1-8 \mathrm{~h}$ & $0.02-0.2$ \\
\hline Passive sampling & Radiello ${ }^{\circledR}$ Cartridge & DNPH derivatization HPLC analysis & $8-48 \mathrm{~h}$ & $0.07-0.4$ \\
\hline Continuous analyzer & IRCE UV analyzer & UV detection & $5 \min$ & 0.2 \\
\hline Continuous analyzer & CEA Fluo analyzer & Fluo detection & $10 \mathrm{~min}$ & 0.4 \\
\hline Continuous sensor & INTERSCAN $^{\circledR}$ & Electrochemical detection & A few tens of seconds & 5 \\
\hline
\end{tabular}

Passive sampling tubes were Radiello ${ }^{\circledR}$ chemiadsorbing cartridge code 165 (introduced in the blue diffusive body code 120-1) purchased from The Fondazione Salvatore Maugeri (FSM; Padova, Italy). Two sampling times were tested: 8 and $48 \mathrm{~h}$. The sampling flow rate was the value given by the FSM: $99 \mathrm{~mL} \mathrm{~min}^{-1}$. This sampling rate varies as a function of the temperature as expressed by the following equation (as determined by FSM): $Q_{\mathrm{k}}=(K / 298)^{0.35}$ where $Q_{\mathrm{K}}$ is the sampling rate at the temperature $K$ and $Q_{298}$ is the reference value at $298 \mathrm{~K}$. Therefore, temperature is monitored throughout the whole exposure time.

Detection limits for both active and passive methods have been determined based on the standard procedure NF ISO 11843-2, 2000 (Table 1). They are given in $\mu \mathrm{g} \mathrm{m}^{-3}$ for each performed sampling time.

The continuous analyzer developed by the CEASaclay laboratory is based on the use of nanoporous transparent matrices made via sol-gel processes and doped with a colorimetric agent, Fluoral-P and the fluorescence reaction product fast detection. The use of an exposure in a pulsed mode allows a $7 \mathrm{~h}$ monitoring with a 10-min frequency. The calibration range is 1 to $200 \mathrm{ppb}$ of $\mathrm{HCHO}$ within $0 \%$ to $60 \%$ of relative humidity. The interference of water implicates the use of a dessicant above $60 \%$ of humidity. A detailed presentation of the technique is given in Paolacci et al. 2007. Detection limit given in Table 1 corresponds to the lowest concentration which can be measured by the instrument and is part of the calibration curve.

The other continuous analyzer was completely fulfilled in IRCELYON laboratory. It is based on formaldehyde trapping in a 3-methylbenzthiazolinone-2-hydrazone solution in acid media by means of a turning coil sampler tube through which air and aqueous solution flow concurrently (François et al. 2005; Lee and Wang 2004; Sauer et al. 2003), derivatisation with a blue cation UV detected by light reflection through a capillary. Liquid core waveguide LCW (810 $\mu \mathrm{m}$ i.d.) Teflon ${ }^{\circledR}$ AF-2,400 tube (Biogeneral, San Diego, CA) was used as an innovative optical cell combining long optical path and minor volume for high sensitivity (Genfa and Dasgupta 1989). The detection limit given in Table 1 has been determined as four times the background noise.

The portable commercialized INETRSCAN ${ }^{\circledR} 4,000$ series analyzer, based on electrochemical titration with a few tens of second time response, was purchased from Interscan Corporation (Chatsworth, Canada). The detection limit given in Table 1 is the value given by the company.

Simulated atmosphere (exposure chamber) experiments

A 150 L Pyrex exposure chamber was used to test, under controlled conditions of temperature, relative humidity and wind speed, the formaldehyde monitoring technique presented here above. A full description of the exposure chamber is given in Gonzalez-Flesca and Frezier 2005. The chamber operating conditions were $20^{\circ} \mathrm{C}, 50 \%$ relative humidity, $1 \mathrm{~m} \mathrm{~s}^{-1}$ wind speed. This wind speed velocity has been chosen because it ensures the atmosphere homogeneity in the chamber. Moreover, even if wind speed is supposed to be very low in indoor environments, it can reach values such as $0.3 \mathrm{~m} \mathrm{~s}^{-1}$ in unventilated workplaces (Baldwin and Maynard 1998) and can be significant in air exhaust system equipped places.

Formaldehyde was introduced in the chamber with a 10 ppm gaseous standard. Relative humidity and pollutant concentration are controlled by diluting with zero air. Each gas (zero air, formaldehyde, and humid air) flow rate introduced in the chamber is controlled by a mass flow controller. The formaldehyde concentrations were set to about $10 \mu \mathrm{g} \mathrm{m}^{-3}$ to simulate low formaldehyde levels usually measured in indoor air, and about $25 \mathrm{\mu g} \mathrm{m}^{-3}$ to simulate medium indoor concentration levels. It should be pointed out that accurate formaldehyde generation in the chamber, based only on the controlled dilution system is not possible because of dilution in water or chamber walls losses. That is why the real generated concentration is often bellow the theoretical concentration and is controlled with active samplings on DNPH cartridges. These concentration conditions will be referred to as "low-" and "highexperimental conditions" respectively. Gaseous standard mixture was purchased from Air Liquide (Mitry-Mory, France). For each experiment, six passive Radiello ${ }^{\circledR}$ tubes 
and one used as a blank were introduced in the chamber meanwhile the other techniques were connected on the chamber. Two Radiello ${ }^{\circledR}$ exposure times have been tested, 8 and $48 \mathrm{~h}$, to evaluate the influence of sampling periods on passive sampling. For each condition of exposure time and concentration, two experiments have been performed. About 8 to $10 \mathrm{~h}$ of active samplings on Sep-Pack ${ }^{\circledR}$ cartridges were carried out to cover the whole passive tubes exposure period and the measurement of continuous monitoring systems.

Blank experiments (sampling on the exposure chamber with each technique except passive tubes which have to be introduced in it) have been carried out without any formaldehyde injected into the chamber.

The exposure chamber experiments conditions as well as instruments deployed are given in Table 2.

Real atmosphere (indoor environments) experiments

The same methodology has been employed in real indoor atmospheres: an office, a furniture shop, a shopping mall and dwellings. In the kitchen and living room of one of the dwellings, several potential formaldehyde sources have been tested: use of cleaning products and ironing, respectively. Table 3 describes the different indoor environments and the technique deployed.

Table 2 Exposure chamber experiments description

\begin{tabular}{|c|c|c|c|}
\hline $\begin{array}{l}\text { Concentration } \\
\text { condition }\end{array}$ & $\begin{array}{l}\text { Number of } \\
\text { experiment }\end{array}$ & $\begin{array}{l}\text { Exposure } \\
\text { time }\end{array}$ & $\begin{array}{l}\text { Deployed } \\
\text { techniques }\end{array}$ \\
\hline Low & 2 & $8 \mathrm{~h}$ & $\begin{array}{l}\text { Radiello }^{\circledR} \\
\left.\text { Sep-Pack }^{(}\right)\end{array}$ \\
\hline High & 2 & $8 \mathrm{~h}$ & $\begin{array}{l}\text { Radiello }^{\circledR} \\
\text { Sep-Pack }\end{array}$ \\
\hline Low & 1 & $48 \mathrm{~h}$ & $\begin{array}{l}\text { Radiello }^{\circledR} \\
\text { Sep-Pack } \\
\text { IRCE UV analyzer } \\
\text { CEA Fluo analyzer }\end{array}$ \\
\hline Low & 1 & $48 \mathrm{~h}$ & $\begin{array}{l}\text { Radiello }^{\circledR} \\
\text { Sep-Pack }^{\circledR} \\
\text { INTERSCAN }^{\circledR}\end{array}$ \\
\hline High & 1 & $48 \mathrm{~h}$ & $\begin{array}{l}\text { Radiello }^{\circledR} \\
\text { Sep-Pack } \\
\text { IRCE UV analyzer } \\
\text { CEA Fluo analyzer }\end{array}$ \\
\hline High & 1 & $48 \mathrm{~h}$ & $\begin{array}{l}\text { Radiello }^{\circledR} \\
\text { Sep-Pack }^{\circledR} \\
\text { INTERSCAN }^{\circledR}\end{array}$ \\
\hline
\end{tabular}

Table 3 Indoor environment experiments description

\begin{tabular}{|c|c|c|}
\hline Indoor environments & $\begin{array}{l}\text { Exposure } \\
\text { time }\end{array}$ & $\begin{array}{l}\text { Deployed } \\
\text { techniques }\end{array}$ \\
\hline Shopping mall & $8 \mathrm{~h}$ & $\begin{array}{l}\text { Radiello }^{\circledR} \\
\text { Sep-Pack }\end{array}$ \\
\hline Furniture shop & $8 \mathrm{~h}$ & $\begin{array}{l}\text { Radiello }^{\circledR} \\
\text { Sep-Pack }\end{array}$ \\
\hline Firm office & $48 \mathrm{~h}$ & $\begin{array}{l}\text { Radiello }^{\circledR} \\
\text { Sep-Pack } \\
\text { IRCE UV analyzer } \\
\text { CEA Fluo analyzer }\end{array}$ \\
\hline House office & $48 \mathrm{~h}$ & $\begin{array}{l}\text { Radiello }^{\circledR} \\
\text { Sep-Pack }^{\circledR} \\
\text { INTERSCAN }\end{array}$ \\
\hline House dining room & $48 \mathrm{~h}$ & $\begin{array}{l}\text { Radiello }^{\circledR} \\
\text { Sep-Pack }^{\circledR} \\
\text { INTERSCAN }^{\circledR}\end{array}$ \\
\hline House living room & $48 \mathrm{~h}$ & $\begin{array}{l}\text { Radiello }^{\circledR} \\
\text { Sep-Pack }^{\circledR} \\
\text { INTERSCAN }^{\circledR}\end{array}$ \\
\hline Kitchen Household activities & $\sim 1 \mathrm{~h}$ & INTERSCAN $^{\circledR}$ \\
\hline
\end{tabular}

\section{Results and discussion}

Exposure chamber experiments: standard methods results

A comparison between active and passive sampling for formaldehyde measurements are presented on Table 4 in which passive and active measurements, the ratio measure on blank for Radiello sampling tube and the difference between active and passive are given.

One of the main observations is the high level of blank corresponding to low "Measure/Blank" ratio, which can be linked to a high difference between active and passive measurement. Indeed, for low exposure time $(8 \mathrm{~h})$ and low concentration conditions $\left(\sim 10 \mu \mathrm{g} \mathrm{m}^{-3}\right)$ even for 48 -h exposure time, this ratio is about 2 to 5 , below an insurance quality ratio which can be chosen equal to at least 10 to ensure a representative and quantitative measurement. However, for high concentration conditions and 48-h exposure time, this ratio tends to become satisfactory so is the difference between concentrations measured by each method ( $7 \%$ and $16 \%)$.

These results suggest that the Radiello sampling tubes should not be used for low exposure time experiments $(8 \mathrm{~h})$ whatever the concentration level is, and for $48 \mathrm{~h}$ exposure time when concentration levels are low. They also suggest that on the one hand, some work should be done to improve Radiello passive tubes levels of blank, and that on the other hand cautions should be taken during storage and transport to minimize sources of contaminations. 
Table 4 Mean formaldehyde concentrations measured on the exposure chamber for different experimental condition and exposure time by active and passive sampling

\begin{tabular}{llcccc}
\hline $\begin{array}{l}\text { Concentration } \\
\text { condition }\end{array}$ & $\begin{array}{l}\text { Exposure } \\
\text { time }\end{array}$ & $\begin{array}{l}\text { Passive } \\
\left(\mu \mathrm{g} \mathrm{m}^{-3}\right)\end{array}$ & Measure/Blank & $\begin{array}{l}\text { Active } \\
\left(\mu \mathrm{g} \mathrm{m}^{-3}\right)\end{array}$ & $\begin{array}{l}\text { Difference active- } \\
\text { passive (\%) }\end{array}$ \\
\hline Low & $8 \mathrm{~h}$ & 7.6 & 2 & 5.2 & -37 \\
Low & $8 \mathrm{~h}$ & 8.7 & 2 & 5.6 & -42 \\
High & $8 \mathrm{~h}$ & 25.8 & 4 & 20.3 & -24 \\
High & $8 \mathrm{~h}$ & 24.1 & 3 & 19.9 & -19 \\
Low & $48 \mathrm{~h}$ & 6.7 & 5 & 7.9 & 17 \\
Low & $48 \mathrm{~h}$ & 11.4 & 6 & 7.5 & -41 \\
High & $48 \mathrm{~h}$ & 17.8 & 15 & 16.7 & -7 \\
High & $48 \mathrm{~h}$ & 32.7 & 52 & 27.7 & -17 \\
\hline
\end{tabular}

Exposure chamber experiments: continuous methods results

In Fig. 1, formaldehyde concentration evolution in the exposure chamber, as measured by each method at their original time resolution, the UV and fluorescence continuous measurement techniques, passive and active sampling techniques, is shown. The mean concentration on the whole experiment period measured by each method is also given. This is an example of 1-day formaldehyde monitoring on the exposure chamber under "high-experimental conditions". On this particular day, the passive sampling tubes were introduced in the exposure chamber, requiring its opening and consequently causing a formaldehyde concentration decrease.

In Fig. 1, the ability of both continuous analyzers to measure this concentration decrease can be observed. However, the UV analyzer response to that decrease is not immediate. The time delay of about an hour can be explained by the instrument memory effect and its analysis time resolution (20 $\mathrm{min}$ ).

Furthermore, because of the different instruments measurement intervals, each of the continuous data set was integrated and average formaldehyde concentrations were calculated on a common time scale to enable their comparison with standard methods. Mean concentrations are given in Fig. 1: before the chamber opening and therefore the passive tubes introduction in the chamber, the mean concentration measured by the two continuous methods (18.4 and $15.8 \mathrm{\mu g} \mathrm{m}^{-3}$ for UV and fluorescence respectively) and the active method $\left(16.8 \mu \mathrm{g} \mathrm{m}^{-3}\right)$ was $17 \mathrm{\mu g} \mathrm{m}^{-3}$ with a relative standard deviation of $8 \%$. After the chamber opening, the mean concentration measured by the two continuous methods (12.2 and $12.2 \mu \mathrm{g} \mathrm{m}^{-3}$ for UV and fluorescence respectively) and the standard methods (14.3 and $17.8 \mathrm{\mu g} \mathrm{m}^{-3}$ for active and passive, respectively) was $14 \mu \mathrm{g} \mathrm{m}^{-3}$ with a relative standard deviation of $18 \%$. Therefore, a good agreement can be observed with satisfactory standard deviation between each technique equal before and after the chamber opening.

Indoor environment experiments: standard methods results

A comparison between active and passive sampling for formaldehyde measurement is presented on Table 5 .
Fig. 1 Time series of formaldehyde concentrations during a "high-experimental conditions" exposure chamber experiment. Measurements of the individual instruments are given at their original time resolution. For each method, the mean measured concentration on whole experiment period, before and after the chamber opening, is given in italic $\left(\mu \mathrm{g} \mathrm{m}^{-3}\right)$

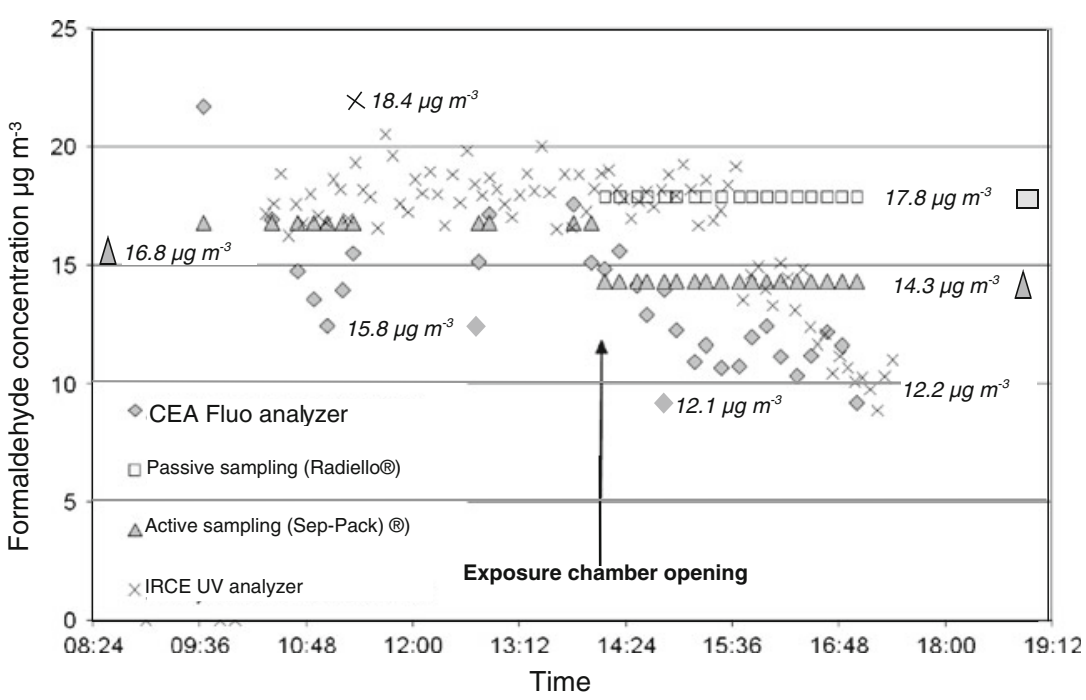


Table 5 Mean formaldehyde concentrations measured in each indoor environment by active and passive sampling

\begin{tabular}{llcccc}
\hline $\begin{array}{l}\text { Indoor } \\
\text { environments }\end{array}$ & $\begin{array}{l}\text { Exposure } \\
\text { time }\end{array}$ & $\begin{array}{l}\text { Passive } \\
\left(\mu \mathrm{g} \mathrm{m}^{-3}\right)\end{array}$ & Measure/Blank & $\begin{array}{l}\text { Active } \\
\left(\mu \mathrm{g} \mathrm{m}^{-3}\right)\end{array}$ & $\begin{array}{l}\text { Difference active- } \\
\text { passive (\%) }\end{array}$ \\
\hline Shopping mall & $8 \mathrm{~h}$ & 19.0 & 5 & 13.5 & -34 \\
Shopping mall & $8 \mathrm{~h}$ & 16.6 & 6 & 11.2 & -38 \\
Furniture shop & $8 \mathrm{~h}$ & 40.0 & 10 & 34.3 & -15 \\
Firm office & $48 \mathrm{~h}$ & 22.2 & 17 & 27.9 & 23 \\
House office & $48 \mathrm{~h}$ & 39.4 & 31 & 41.1 & 1 \\
House dining room & $48 \mathrm{~h}$ & 38.6 & 28 & 37.8 & -1 \\
House living room & $48 \mathrm{~h}$ & 57.6 & 42.4 & 55.4 & -4 \\
\hline
\end{tabular}

As for exposure chamber experiments, passive tubes high levels of blank can affect formaldehyde measurement resulting in an important difference between active and passive methods (from $15 \%$ to $34 \%$ ). A good agreement is observed between both techniques when the measure/blank ratio becomes high enough. This difference is very low (from $4 \%$ to $1 \%$ ) in comparison with the values measured during exposure chamber experiment (from $37 \%$ to $17 \%$ ) as shown in Table 4 and the campaign in the shopping mall (from $34 \%$ to $15 \%$ ). The main difference between these two sets of experiments is the wind speed. Indeed, in the exposure chamber, a wind speed of $1 \mathrm{~m} \mathrm{~s}^{-1}$ was simulated and in the shops, an air exhaust system was operating whereas there was no mechanical ventilation in the private houses. This wind speed could explain the passive sampler over-estimation of formaldehyde concentrations. It has indeed been shown that Eddy diffusion caused by air turbulence at the entrance of the sampling tube can lead to a shortening of the diffusion path length and therefore a positive artifact (Sekine et al. 2008).

Indoor environment experiments: continuous methods results and secondary formaldehyde formation monitoring

The three continuous analyzers have been tested in the indoor environments and have shown a good agreement with the active sampling method.
Standards techniques, active and passive formaldehyde measurement and both continuous in development analyzers, IRCE UV and CEA Fluo, have been tested in an office as shown in Fig. 2. It presents 1-day formaldehyde monitoring in an office with formaldehyde concentration decrease due to door opening during the day. The office door was closed the day before the beginning of the experiment to ensure the stability of the atmosphere. It was eventually opened during the experiment day since the temperature in the room was rising because of all the functioning apparatus.

Before the office door opening at about 2 p.m., a good agreement between each technique can be observed with a relative standard deviation equal to $6 \%$. Moreover, the formaldehyde decrease linked to door opening is properly monitored by each continuous analyzer. However, after the door opening, a formaldehyde concentrations underestimation of about $25 \%$ in comparison with active sampling can be observed for the CEA Fluo analyzer. Indeed, in the morning, before 2 p.m., CEA analyzer measurements were carried out in an atmosphere with $\sim 60 \%$ of relative humidity. Meanwhile, the nanoporous thin film, which is hydrophilic, was filled with water. After that, the film cannot dry properly by exposure to the "after 2 p.m. atmosphere" which still contain $50 \%$ relative humidity
Fig. 2 Time series of formaldehyde concentrations in an office experiment. Measurements of the individual instruments are given at their original time resolution. For each method, the mean measured concentration on whole experiment period, before and after the door opening, is given in italic $\left(\mu \mathrm{g} \mathrm{m}^{-3}\right)$

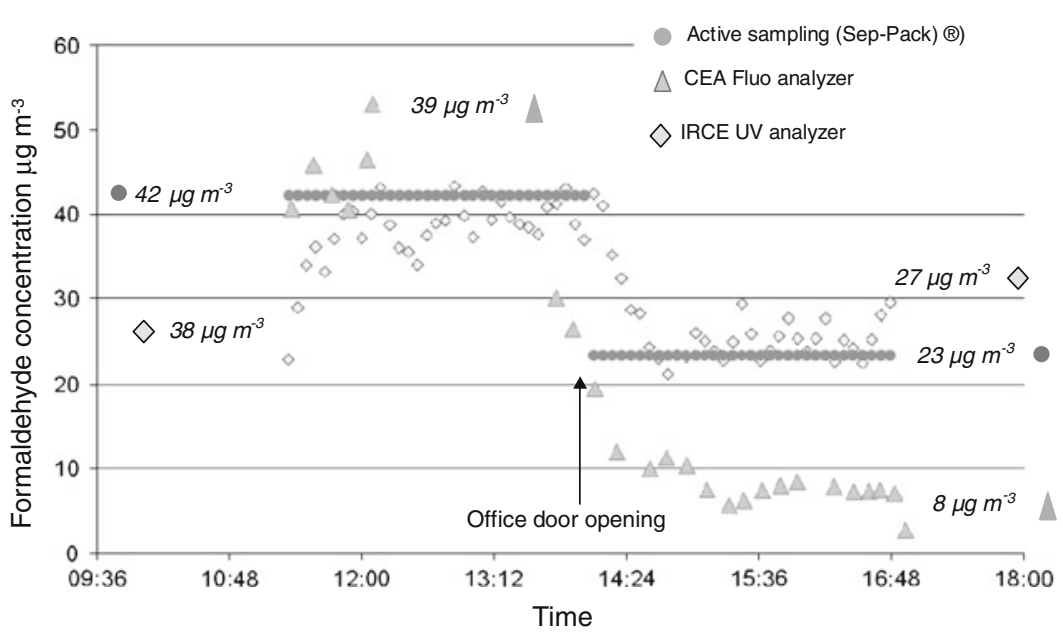


Another series of indoor experiments have been led with the portable commercialized analyzer INTERSCAN ${ }^{\circledR}$ to check for its capacity to measure formaldehyde.

These experiments took place in two different dwellings, in the office and living room of the first one, in the living room and kitchen of the second one. INTERSCAN ${ }^{\circledR}$ measurements were compared to active measurement. Even if the portable commercialized analyzer provides brief measurement of a few tens of seconds and Sep-Pack ${ }^{\circledR}$ a few hours integrated measurement, the formaldehyde concentrations in the rooms could be considered as constant since no particular activity was carried out and no door or windows have been opened. Whenever the comparison was made, results from both techniques were similar with relative standard deviation ranging from $7 \%$ to $22 \%$. As an example, for the house office experiment, measured concentrations where 26 and $28 \mathrm{\mu g} \mathrm{m}^{-3}$ by Sep-Pack and INTERSCAN ${ }^{\circledR}$ respectively, while for one of the house dining room experiments, they were 38 and $35 \mu \mathrm{g} \mathrm{m}^{-3}$.

Last experiment was also carried out with the portable commercialized analyzer INTERSCAN ${ }^{\circledR}$ to monitor the potential formaldehyde formation following domestic activities (ironing, household...). Firstly, experiment concerned ironing and was performed in the living room where the background formaldehyde concentrations were about $40 \mathrm{\mu g} \mathrm{m}^{-3}$. When living the stirrer a few minutes on the stirring table consequently heating the table protecting foam, the INTER$\mathrm{SCAN}^{\circledR}$ could measure a formaldehyde concentration increase to about $90 \mu \mathrm{g} \mathrm{m}^{-3}$ showing the ability of the analyzer to measure concentration variations. It also enlightens the potentiality of such material to emit formaldehyde when heated.

Eventually, an experiment took place in a kitchen where the formaldehyde concentration background was about $40 \mathrm{\mu g} \mathrm{m}^{-3}$ as monitored by Sep-Pack ${ }^{\circledR}$ and INTERSCAN ${ }^{\circledR}$. Then, cleaning products have been used. A table was cleaned and no formaldehyde concentration increase has been immediately observed. A few minutes later, the windowpanes have been washed with a glass cleaner and no change in formaldehyde concentration could be observed with the analyzer. 15 min after the cleaning products use, an increase of formaldehyde concentrations in the kitchen could be monitored by the analyzer as shown in Fig. 3. This may result from chemical reaction between airborne pollutants such as terpenes (limonene) widely used in such housekeeping products (Nazaroff and Weschler 2004), and Ozone (Bonn et al. 2002; Weschler 2006; Wolkoff et al. 2008), enlightening formaldehyde secondary formation as already observed by Solal et al. 2008. It can be observed in Fig. 3 that formaldehyde reaches a very high concentration value of about $200 \mu \mathrm{g} \mathrm{m}^{-3}$. Such a concentration does not seem to be really realistic and should not correspond to formaldehyde measurement only. Indeed, further studies should be carried out to evaluate the selectivity of the portable commercialized analyzer on the one hand and try to identify and quantify all the secondary products formed from limonene reaction on the other hand.

Indoor environment experiments: formaldehyde measured concentrations

As it can be seen in the summarizing table (Table 6), mean formaldehyde concentrations measured in indoor environments range from 40 to $54 \mu \mathrm{g} \mathrm{m}^{-3}$. These values can be compared for example to ATSDR minimum risk level value of $50 \mu \mathrm{g} \mathrm{m}^{-3}$ for a zero to 15 days exposure in relation to eyes and nose irritation (ATSDR 1999) and OEHHA chronic reference exposure level of $3 \mu \mathrm{g} \mathrm{m}^{-3}$, for more than a year exposure in relation to respiratory and eye irritations (OEHHA 1999). In France, guide values have been set to
Fig. 3 Formaldehyde time series monitored by the portable commercial analyzer during the use of housekeeping products

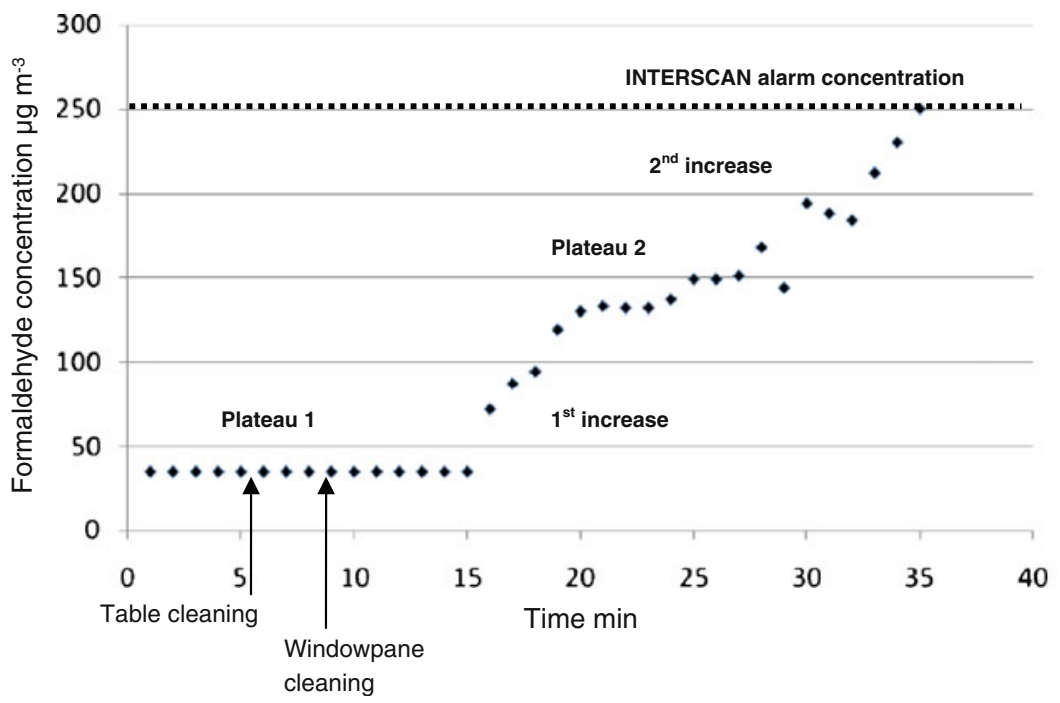


Table 6 Summarizing table giving mean formaldehyde concentrations $\left(\mu \mathrm{g} \mathrm{m}^{-3}\right)$ and standard deviations (\%) between each technique for all the experiments

Chamber experiments

\begin{tabular}{|c|c|c|c|c|}
\hline Concentration condition & Experiment time & Deployed techniques & Mean concentration $\mu \mathrm{g} \mathrm{m}^{-3}$ & $\begin{array}{l}\text { Standard deviation on each } \\
\text { technique } \%\end{array}$ \\
\hline Low & $8 \mathrm{~h}$ & $\begin{array}{l}\text { Radiello }^{\circledR} \\
\text { Sep-Pack }\end{array}$ & 6.4 & 27 \\
\hline Low & $8 \mathrm{~h}$ & $\begin{array}{l}\text { Radiello }^{\circledR} \\
\text { Sep-Pack }\end{array}$ & 7 & 31 \\
\hline High & $8 \mathrm{~h}$ & $\begin{array}{l}\text { Radiello }^{\circledR} \\
\text { Sep-Pack }\end{array}$ & 23 & 17 \\
\hline High & $8 \mathrm{~h}$ & $\begin{array}{l}\text { Radiello }^{\circledR} \\
\text { Sep-Pack }\end{array}$ & 22 & 13 \\
\hline Low & $48 \mathrm{~h}$ & $\begin{array}{l}\text { Radiello }^{\circledR} \\
\text { Sep-Pack } \\
{ }^{\circledR} \\
\text { IRCE UV analyzer } \\
\text { CEA Fluo analyzer }\end{array}$ & 7.2 & 8 \\
\hline High before chamber opening & $48 \mathrm{~h}$ & $\begin{array}{l}\text { Radiello }^{\circledR} \\
\text { Sep-Pack } \\
\text { IRCE UV analyzer } \\
\text { CEA Fluo analyzer }\end{array}$ & 17 & 7 \\
\hline High after chamber opening & $48 \mathrm{~h}$ & $\begin{array}{l}\text { Radiello }^{\circledR} \\
\text { Sep-Pack } \\
\text { IRCE UV analyzer } \\
\text { CEA Fluo analyzer }\end{array}$ & 13 & 10 \\
\hline \multicolumn{5}{|l|}{ Indoor environments } \\
\hline Shopping mall & $8 \mathrm{~h}$ & $\begin{array}{l}\text { Radiello }^{\circledR} \\
\text { Sep-Pack }^{\circledR}\end{array}$ & 16 & 27 \\
\hline Furniture shop & $8 \mathrm{~h}$ & $\begin{array}{l}\text { Radiello }^{\circledR} \\
\text { Sep-Pack }^{(\mathbb{R}}\end{array}$ & 44 & 11 \\
\hline Firm office & $48 \mathrm{~h}$ & $\begin{array}{l}\text { Radiello }^{\circledR} \\
\text { Sep-Pack } \\
\text { IRCE UV analyzer } \\
\text { CEA Fluo analyzer }\end{array}$ & 40 & 6 \\
\hline House office & $48 \mathrm{~h}$ & $\begin{array}{l}\text { Radiello }^{\circledR} \\
\text { Sep-Pack }^{\circledR} \\
\text { INTERSCAN }^{\circledR}\end{array}$ & 40 & $\begin{array}{l}4 \text { (Radiello/Sep-Peck) } \\
8 \text { (Sep-Pack/interscan) }\end{array}$ \\
\hline House dining room & $48 \mathrm{~h}$ & $\begin{array}{l}\text { Radiello }^{\circledR} \\
\text { Sep-Pack }^{\circledR} \\
\text { INTERSCAN }^{\circledR}\end{array}$ & 38 & $\begin{array}{l}1 \text { (Radiello/Sep-Peck) } \\
8 \text { (Sep-Pack/interscan) }\end{array}$ \\
\hline House living room & $48 \mathrm{~h}$ & $\begin{array}{l}\text { Radiello }^{\circledR} \\
\text { Sep-Pack }^{\circledR} \\
\text { INTERSCAN }^{\circledR}\end{array}$ & 54 & $\begin{array}{l}8 \text { (Radiello/Sep-Peck) } \\
22 \text { (Sep-Pack/interscan) }\end{array}$ \\
\hline Kitchen Household activities & $\sim 1 \mathrm{~h}$ & INTERSCAN $^{\circledR}$ & $40-200$ & \\
\hline
\end{tabular}

help survey formaldehyde in indoor environments, on the basis of toxicological data and usual formaldehyde concentrations measured indoor (HCSP 2009). As an example, in 2009 , the value of $30 \mathrm{\mu g} \mathrm{m}^{-3}$ has been set as an urging value to set up actions to improve air quality.

All the mean formaldehyde values measured indoor during the experiments presented here are above these values, enlightening the imperious need to be provided with efficient technique to survey this pollutant concentrations, indentify sources and reduce them.

\section{Conclusion}

This work aimed at studying the ability of passive sampling tubes and different continuous analysers in comparison to 
active sampling, to measure formaldehyde in indoor environments.

A comparison of the results given by the standard active and passive methods and the three continuous formaldehyde monitoring systems has shown a general good agreement between each technique with standard deviations ranging between $7 \%$ and $25 \%$. Continuous on-line analyzers have been able to measure formaldehyde concentration changes even if their response can be altered by memory effects for the UV analyzer and relative humidity for the florescence analyzer. The negative influence of water on formaldehyde measurement could be overcome by the use of anhydrous filter which is being tested.

Particular attention should be addressed when measuring low formaldehyde concentrations with passive Radiello ${ }^{\circledR}$ diffusion tubes during low exposure time because of the high blank level. Some work should be done to improve Radiello ${ }^{\circledR}$ passive tubes levels of blank and cautions should be taken when storing and caring the sampling tubes to minimize the contamination sources.

Another parameter which could influence formaldehyde adsorption on passive sampler would be the wind speed. Further investigations should be carried out to improve knowledge on such phenomena which could be significant indoor when air exhaust systems are used or when draught are caused by windows opening for instance.

Besides, the cleaning product use clearly shows formaldehyde secondary formation probably linked to terpene ozonolysis. Such experiments should be repeated since the relative contributions of primary and secondary emissions in indoor air remain very difficult to quantify but essential to reduce formaldehyde concentrations.

Revealing formaldehyde measurement method weaknesses on the one hand and showing high concentrations indoor that can be attributed to both primary and secondary sources; this work enlightens the urgent need to be provided with efficient active and passive methods for formaldehyde indoor concentration monitoring and population exposure survey, and online continuous techniques for source emissions and concentration variation monitoring.

Acknowledgment The authors would like to thank the French Ministry of the Environment for supporting this work.

Open Access This article is distributed under the terms of the Creative Commons Attribution Noncommercial License which permits any noncommercial use, distribution, and reproduction in any medium, provided the original author(s) and source are credited.

\section{References}

Andreini BP, Baroni R, Galimberti E, Sesana G (2000) Aldehydes in the atmospheric environment: evaluation of human exposure in the north-west area of Milan. Microchem J 67:11-19
ATSDR (1999) Agency for toxic substances and disease registry, toxicological profile for formaldehyde U.S. Department of Health and Human Services. Public Health Service. Available at: http:// www.atsdr.cdc.gov/. Accessed Jun 1999

Baldwin PEJ, Maynard AD (1998) A survey of wind speeds in indoor workplaces. Ann Occup Hyg 42:303-313

Bates MS, Gonzalez-Flesca N, Sokhi R, Cocheo V (2000) Atmospheric volatile organic compound monitoring. Ozone induced artefact formation. Environ Monit Assesment 65:89-97

Bell W, et al. (2000) A pilot study of formaldehyde monitoring in ambient air. NPL Report COEM S36

Bonn B, Schuster G, Moortgat GK (2002) Influence of water vapour on the process of new particle formation during monoterpene ozonolysis. J Phys Chem A 106:2869-2881

Brown SK (1999) Chamber assessment of formaldehyde and VOC emissions from wood-based panels. Indoor Air 9:209-215

Cardenas LM et al (2000) Intercomparison of formaldehyde measurements in clean and polluted atmospheres. J Atmos Chem 37:5380

Clarisse B et al (2003) Indoor aldehydes: measurement of contamination levels and identification of their determinants in Paris dwellings. Environ Res 92:245-253

Eom IY, Li QY, Li JZ, Dasgupta PK (2008) Robust hybrid flow analyzer for formaldehyde. Environ Sci Technol 42:12211226

François S, Perraud V, Pflieger M, Monod A, Wortham H (2005) Comparative study of glass tube and mist chamber sampling techniques for the analysis of gaseous carbonyl compounds. Atmos Environ 39:6642-6653

Genfa Z, Dasgupta PK (1989) Fluorometric measurement of aqueous ammonium ion in a flow injection system. Anal Chem 61:408 412

Gillett RW, Kreibich H, Ayers GP (2000) Measurement of indoor formaldehyde concentrations with a passive sampler. Environ Sci Technol 34:2051-2056

Gonzalez-Flesca N, Frezier A (2005) A new laboratory test chamber for the determination of diffusive sampler uptake rates. Atmos Environ 39:4049-4056

Hak C et al (2005) Intercomparison of four different in-situ techniques for ambient formaldehyde measurements in urban air. Atmos Chem Phys 5:2881-2900

Hanoune B, Lebris T, Marchand C, Le Calvé S (2006) Formaldehyde measurments in libraries: comparison between infrared diode laser spectroscopy and a DNPH-derivatization method. Atmos Environ 40:5768-5775

HCSP (2009) High council for public health, guide values for indoor air quality management: formaldhyde. Available at: http://www. hcsp.fr/. Accessed 17 Nov 2009

Ho SSH, Yu JZ (2002) Feasibility of collection and analysis of airborne carbonyls by on-sorbent derivatization and thermal desorption. Anal Chem 74:1232-1240

Huynh C-K, Vu-Duc T (2002) Intermethod comparisons of active sampling procedures and analysis of aldehydes at environmental levels. Anal Bioanal Chem 372:654-657

IARC (2004) Overall evaluation of carcinogenicity to humans, formaldehyde (50-00-0). The IARC monographs series 88

ISO 16000-3:2001 (2001) Indoor air-Part 3: determination of formaldehyde and other carbonyl compounds-Active sampling method. Standard, ISO 16000-3:2001 (2001-09-01)

ISO 16000-4:2001 (2004) Indoor air-Part 4: determination of formaldehyde-diffusive sampling method. Standard, ISO 16000-4:2004 (2004-05-15)

Koziel JA, Noah J, Pawliszyn J (2001) Field sampling ann ddetermination of formaldehyde in indoor air with solid-phase microextraction and on-fiber derivatisation. Environ Sci Technol $35: 1481-1486$ 
Lee S-C, Wang B (2004) Characteristics of emissions of air pollutants from burning of incense in a large environmental chamber. Atmos Environ 38:941-951

Loh MM et al (2006) Measured concentrations of VOCs in several non-residential microenvironments in the United States. Environ Sci Technol 40:6903-6911

Marchand C, Bulliot B, Le Calvé S, Mirabel P (2006) Aldehyde measurments in indoor environments in Strasbourg (France). Atmos Environ 40:1336-1345

Nash T (1953) The colorimetric estimation of formaldehyde by means of the Hantsch reaction. Biochem J 55:416-421

Nazaroff WW, Weschler CJ (2004) Cleaning products and air fresheners: exposure to primary and secondary air pollutants. Atmos Environ 38:2841-2865

NF ISO 11843-2 (2000) Capability of detection, Part 2: methodology in the linear calibration case. Standard, NF ISO 11843-2:2000

Observatory on Indoor Air Quality (OQAI) (2006) National survey: indoor air quality in French dwellings

OEHHA (1999) Office of environmental health hazard assessment, determination of chronic reference exposure level for airborne toxicants. Chronic Toxicity Summary. Formaldehyde. Available at: http://www.oehha.ca.gov/. Accessed Mar 1999

Onishi M, Sekine Y, Sugihara K, Kitasaka K, Shimajiri H (2007) A passive sampler for the determination of carbonyl compounds in indoor air employing $O$-(4-cyano-2-ethoxybenzyl) hydroxylamine as reactive adsorbant. J Health Sci 53:413-422

Paolacci H et al (2007) A ppb formaldehyde gas sensor for fast indoor air quality measurement. Sensors transducers 82:1423-1430

Pinheiro HLC, de Andrade MV, de Paula Pereira PA, de Andrade JB (2004) Spectrofluorimetric determination of formaldehyde in air after collection onto silica cartridges coated with Fluoral P. Microchem J 78:15-20
Salthammer T, Mentese S (2008) Comparison of analytical techniques for the determination of aldehydes in test chambers. Chemosphere 73:1351-1356

Sauer CG, Pisano JT, Fitz DR (2003) Tunable diode laser absorption spectrometer measurements of ambient nitrogen dioxide, nitric acid, formaldehyde, and hydrogen peroxide in Parlier, California. Atmos Environ 37:1583-1591

Sauer F, Beck J, Schuster G, Moortgat GK (2001) Hydrogen peroxide, organic peroxides and organic acids in a forested area during FIELDVOC'94. Chemosphere Glob Change Sci 3:309-326

Sekine Y, Watts SF, Rendell A, Butsugan M (2008) Development of highly sensitive passive sampler for nitrogen dioxide using porous polyethylene membrane filter as turbulence limiting diffuser. Atmos Environ 42:4079-4088

Solal C, Rousselle C, Mandin C, Manel J, Maupetit F (2008) VOCs and formaldehyde emissions from cleaning products and air fresheners. Indoor Air Confernence, Copenhague, Denmark

Toda K, Yoshioka K-I, Mori K, Hirata S (2005) Portable system for nearreal time measurement of gaseous formaldehyde by means of parallel scrubber stopped-flow absorptiometry. Anal Chim Acta 531:41-49

Weschler CJ (2006) Ozone's impact on public health: contributions from indoor exposures to ozone and products of ozone-initiated chemistry. Environ Health Perspect 114:1489-1496

Wisthaler $\mathrm{A}$ et al (2008) Technical note: intercomparison of forùmaldehyde measurments at the atmosphere simulation chamber SAPHIR. Atmos Chem Phys 8:2189-2200

Wolkoff P et al (2008) Acute air effects of ozone-initiated d-limonene chemistry: importance of gaseous products. Toxicol Lett 181:171-176

Zhang J, Lioy PJ, He Q (1994) Characteristics of aldehydes: concentrations, sources, and exposures for indoor and outdoor residential microenvironments. Environ Sci Technol 28:146-152 